\title{
Effects of topographic data resolution and spatial model resolution on a bi-dimensional hydro-morphological model
}

\author{
E. Frank ${ }^{1}$, M. Montoya ${ }^{2}$ \& S. Fattorelli ${ }^{1,2}$ \\ ${ }^{1}$ Beta Studio srl, Italy \\ ${ }^{2}$ Padova University, Italy
}

\begin{abstract}
Uncertainties in topographic data may have a significant influence on morphological and hydraulic predictions. In this work, the effects of topographic data resolution and model resolution (dimension of the cell) on the results of a morphological and sediment transport model are analysed using the morphological bi-dimensional curvilinear model MIKE 21C. The study was carried out on the river Torre, located in north-east Italy. Two sources of topographic data were used to create model bathymetry, one based on high-resolution LiDAR (Light Detection And Ranging) data, and the second on river cross-section data. Digital elevation models were created with these topographic data, in order to test the effect of various spatial resolutions. Numerical simulation was carried out for each digital elevation model with different cell dimensions. The impact of topographic information on hydraulic and morphological model results was evaluated by means of three criteria: a) comparison of hydrodynamic results, b) analysis of morphologic variations along the watercourse, c) position of erosional and depositional zones along the watercourse. This study emphasises the importance of input quality information for reliable results of morphological and sediment transport models. Criteria for selecting the optimal dimensions of the cell model are suggested, based on the quality of available data.
\end{abstract}

Keywords: topographical resolution, LiDAR, hydro-morphological model, sediment transport. 


\section{Introduction}

Accurate representation of topography and appropriate spatial resolution models are of prime importance in hydraulic and morphological modelling. Although, the first point has been studied by many researchers, [1-6], the second has been scantily treated.

There is often a dilemma in selecting the resolution of Digital Elevation Model (DEM): a low-resolution DEM results in a larger loss of information, and a high-resolution one takes up excessive computational time. Successful 2D modelling is reported (Haile and Rientjes [3]), for topographically simple areas where low-resolution DEM (created from traditional survey data) is commonly used as model input. In recent years, developments in airborne remote sensing data capturing techniques such as "Light Detection And Ranging" (LiDAR) has supported the use of high-resolution data; consequently, high-quality DEM can serve as inputs in 2D hydraulic and sediment transport modelling. Therefore, in practical cases, it is important to evaluate errors between results obtained with different sources of topographical information.

A major disadvantage of the use of low-resolution input model data is the loss of important small-scale features that affect the sediment transport process (meander migration, formation of point and central bars).

The aim of this paper is to study the effect of topographic data (LiDAR, cross-section) and spatial model resolution (five grids) on hydro-morphological variables simulated with bi-dimensional model MIKE21C. This study indicates that differing resolutions on topographic data and diverse cell dimensions produce important dissimilarities in simulation results, concerning morphological variations (distribution of sediment transport patterns, erosion rates) and flow hydraulics (flow mitigation, propagation time, water depth). Comparing model results obtained with different grid dimensions, from high to lower resolution, important bed details are lost, mainly as a consequence of averaging and internal interpolations of bathymetry data, which influences model performance and the reliability of simulation results.

\section{Description of the model}

In this study, the bi-dimensional hydro-morphological model MIKE 21C, developed by DHI [7], was used. This uncoupled model is based on a so-called orthogonal curvilinear grid, which solves the vertically integrated equations of continuity and conservation of momentum (De Saint Venant equations). These equations are solved by implicit difference techniques, with variables defined on a space-staggered computational grid. The hydrodynamic solution is used to evaluate solid transport and the continuity equation of the sediment and, consequently, yields an estimation of morphological state. At each calculation time step, the model updates the curvilinear grid and represents erosion and deposition processes dynamically. This means that there is feedback between sediment transport and hydrodynamic conditions. 
The model simulation requires: a) topographic information (curvilinear grid and DEM), b) hydrodynamic boundary and initial conditions, c) sediment characteristics of bed (mean diameter, number of fractions, layer thickness and sediment fraction maps), and d) model coefficients (resistance, helical flow, transverse slope, etc).

\subsection{Study area}

The river Torre (fig. 1) rises in the Italian Dolomites and ends at its confluence with the river Isonzo (north-east Italy). It has a length of $66 \mathrm{~km}$ and a drainage area of $1091 \mathrm{~km}^{2}$. Its braided riverbed is formed of central islands partially covered with vegetation and extended floodplain areas, often used for agriculture. The system is characterised by impulsive flood waves, with a peak discharge of $2599 \mathrm{~m}^{3} / \mathrm{s}\left(\mathrm{T}_{\mathrm{R}}=100\right.$ years) for a precipitation of 12 hours (BETA Studio srl. [8]). The mean grain size $\left(D_{50}\right)$ of the riverbed varies between 90 and $10 \mathrm{~mm}$.

The portion of Torre analysed in this work is $12 \mathrm{~km}$ long (slope, $\mathrm{S}=0.0046$ ). This is characterised by peak discharge of $670 \mathrm{~m}^{3} / \mathrm{s}\left(\mathrm{T}_{\mathrm{R}}=100\right.$ years $)$ for a precipitation of 12 hours (BETA Studio srl. [8]). The riverbed is mainly composed of gravel, which dominates sediment movement. This reach is crossed by several structures (bridges, dams) which influence its hydraulic and morphological behaviour.
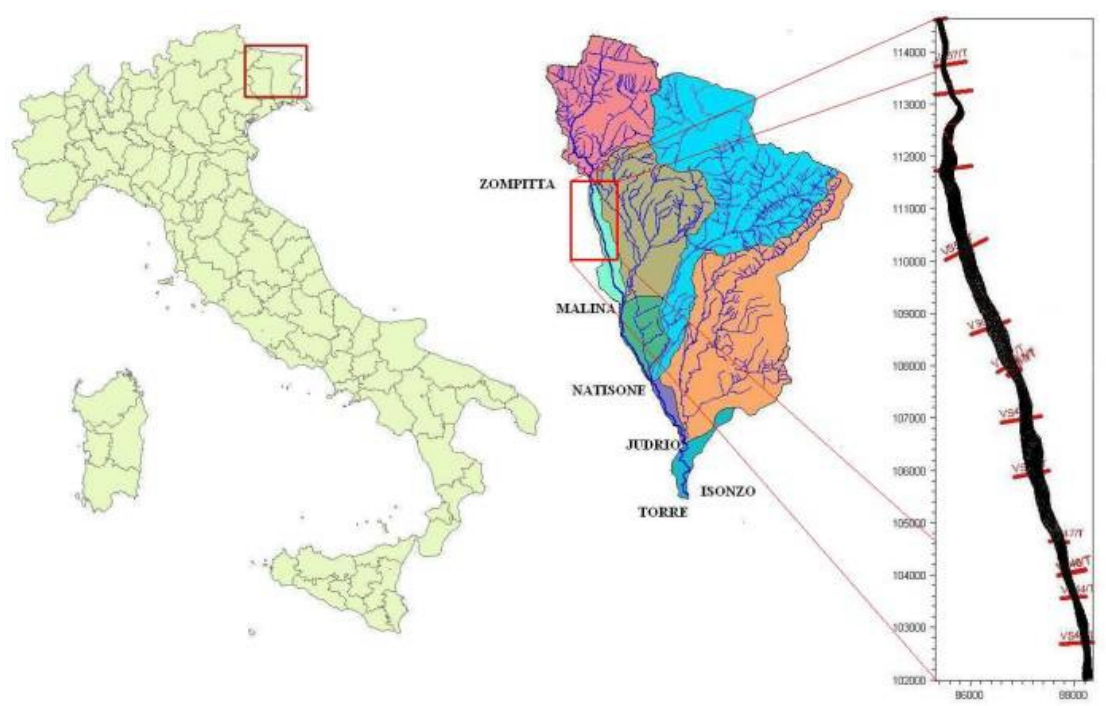

Figure 1: Location of the study area, where last part represents analysed reach of $12 \mathrm{~km}$. 


\subsection{Input data of the model}

Two sources of topographic data were used to create two different sets of model bathymetry, the first based on high-resolution LiDAR data varying between 0.3 4 point $/ \mathrm{m}^{2}$, and the second on data from 15 river cross-sections (from 58 to 43 ), separated by approximately $900 \mathrm{~m}$, with an average width of $170 \mathrm{~m}$. The latter was constructed by joining the principal points (upper-down banks on right and left sides, bottom) of the cross-section through five 3D-lines, with linear variation of elevation, according to the river plan-form derived from orthophotos and the Regional Technical Map.

A preliminary study of inundated areas was carried out, to define model limits accurately. Then a curvilinear grid of the riverbed was constructed, considering floodplains and following streamline directions, stream banks, levees, hydraulic structures, etc. Five computational grids with different resolution were constructed (fig. 2). The main characteristics are listed in table 1.

Two digital terrain models ( $2 \mathrm{~m} \times 2 \mathrm{~m}$ grid) were generated from the basic topographical information, the first from LiDAR data (bathymetry 'a') and the

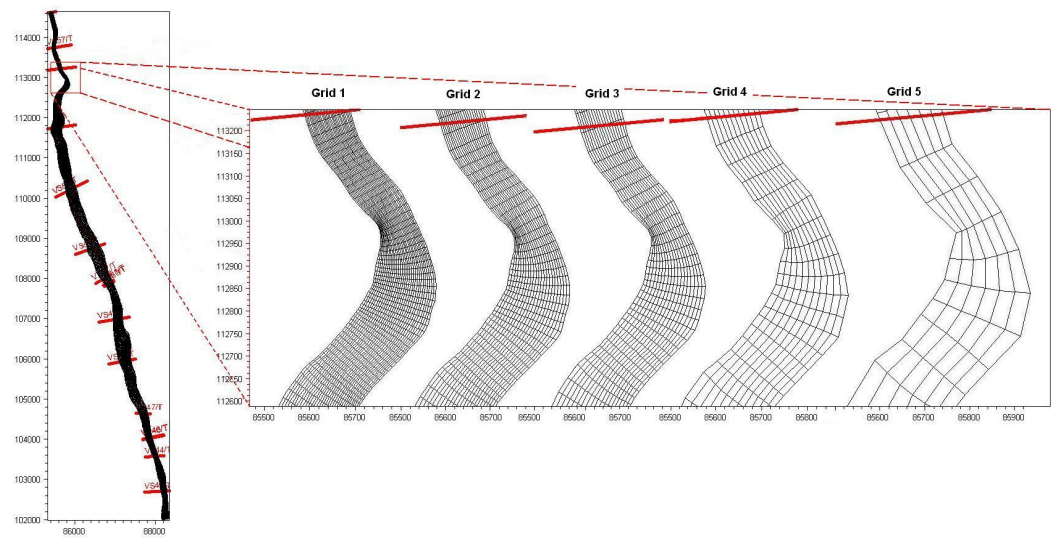

Figure 2: Curvilinear grids constructed with different cell dimensions. Grid order is shown according to refinement.

Table 1: Characteristics of computed grids. Average cell dimensions in cross-sectional direction $(d n)$, in motion direction $(d s)$, and number of cells is reported for each grid.

\begin{tabular}{|c|c|c|c|c|c|c|}
\hline \multirow{2}{*}{$\begin{array}{c}\text { Grid } \\
\text { number }\end{array}$} & \multicolumn{2}{|c|}{ Average dimensions } & \multicolumn{3}{|c|}{ Number of grid cells } \\
\cline { 2 - 7 } & $\begin{array}{c}d n \\
(\mathrm{~m})\end{array}$ & $\begin{array}{c}d s \\
(\mathrm{~m})\end{array}$ & $\begin{array}{c}d A, \text { area } \\
\left(\mathrm{m}^{2}\right)\end{array}$ & $\begin{array}{c}\text { Cross-sectional } \\
\text { direction }\end{array}$ & Motion direction & Total \\
\hline 1 & 7 & 29 & 205 & 29 & 452 & 13108 \\
\hline 2 & 10 & 42 & 426 & 20 & 318 & 6360 \\
\hline 3 & 12 & 52 & 659 & 16 & 255 & 4080 \\
\hline 4 & 22 & 88 & 1998 & 9 & 149 & 1341 \\
\hline 5 & 49 & 177 & 8995 & 4 & 74 & 296 \\
\hline
\end{tabular}


second from cross-sectional data (bathymetry ' $b$ '). These constituted the input data for the automatic generation of the curvilinear grid bathymetry in the MIKE $21 \mathrm{C}$ model.

For hydraulic boundary conditions, a flood with $T_{R}=20$ years was set at the model inlet boundary (peak discharge $459 \mathrm{~m}^{3} / \mathrm{s}$ ) and variable water depth, calculated according of the hydrograph, at the outlet section. A value of bed level change of zero was assumed upstream and downstream, in order to avoid numerical instabilities. Sediment transport at the inlet was considered to be zero, due to the presence of a dam at the beginning of the reach.

Solid transport is described exclusively as bed load, due to gravels movement. For this reason, it was estimated with the empirical equation of Smart and Jaeggi [9]. Three sediment fractions (15, 30 and $50 \mathrm{~mm}$ ) were used to describe grain size distribution in the channel, and two homogeneous reaches were defined with different percentages of these fractions.

\subsection{Results}

The impact of topographic information and the resolution of computational grids on hydro-morphological model results, was evaluated by means of three criteria: a) comparison of hydrodynamic results, b) analysis of morphologic variations in selected cross-sections, c) position of erosional and depositional zones along the watercourse.

Regarding hydrodynamic results, the following comparisons are presented: liquid peak discharges at the outlet of the studied reach, lag time between upstream-downstream peak discharges, and maximum water levels in a representative portion of the river reach.

Liquid peak discharges $\left(\mathrm{Q}_{\mathrm{L}}\right)$ at the outlet of the reach, calculated with different grid dimensions and the two model bathymetries, are shown in the fig. 3(a). Note that the peak discharges obtained with LiDAR topographic data, show similar values for the three first grids, and thereafter decrease. The lag time (fig. $3(b)$ ) increases from grid 1 to grid 5 . With decreasing grid resolution, there is a smoothing effect of riverbed irregularities, which generates larger cross-sections and lower water depths. As a consequence, slower flow and higher flood wave mitigation are produced. Considering the cross-sectional data, note that, for the different grids, the $\mathrm{Q}_{\mathrm{L}}$ values are similar, while lag time are lower than the corresponding ones calculated with LiDAR data. These tendencies may be explained by the raw bathymetry effect, due to the lack of data between two following cross-sections. This generates a bathymetry with fewer curves (straight channel) and does not accurately describe morphological features (islands, bars), resulting in a lag time that, for grid 1, is almost half that calculated with bathymetry ' $a$ '. The same effect due to grid size described above for bathymetry ' $a$ ' is also observed in this case.

An example of simulated maximum water level, with different resolutions of topographical model and grid dimensions, is shown in fig. 4. The greater dissimilarity is produced with model bathymetry ' $b$ ', originating from the traditional topographical survey. In this case, using the largest cell dimension (grid 5) causes uniformity of maximum water levels, which is greater than the 
smallest cell dimension (grid 1). This is clear considering that the riverbed is more homogeneous and morphological bed details like central and point bars are lost (fig. 4).

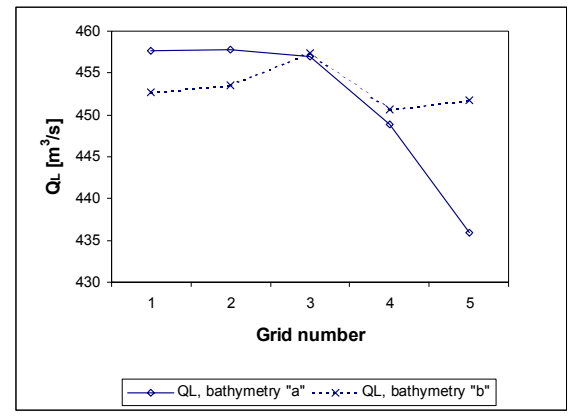

(a)

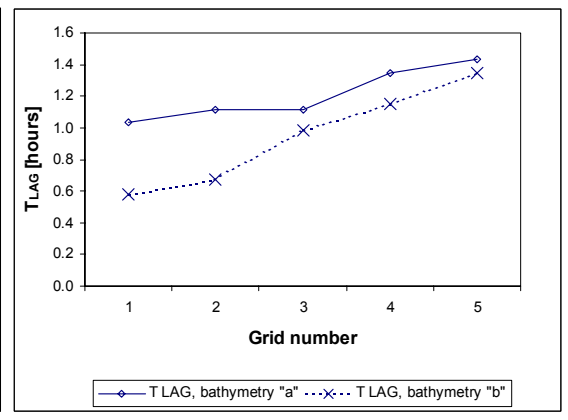

(b)

Figure 3: $\quad$ Comparison of: (a) liquid peak discharges downstream of reach; (b) lag time for hydrodynamic simulation with different resolution data (grid and model bathymetry).

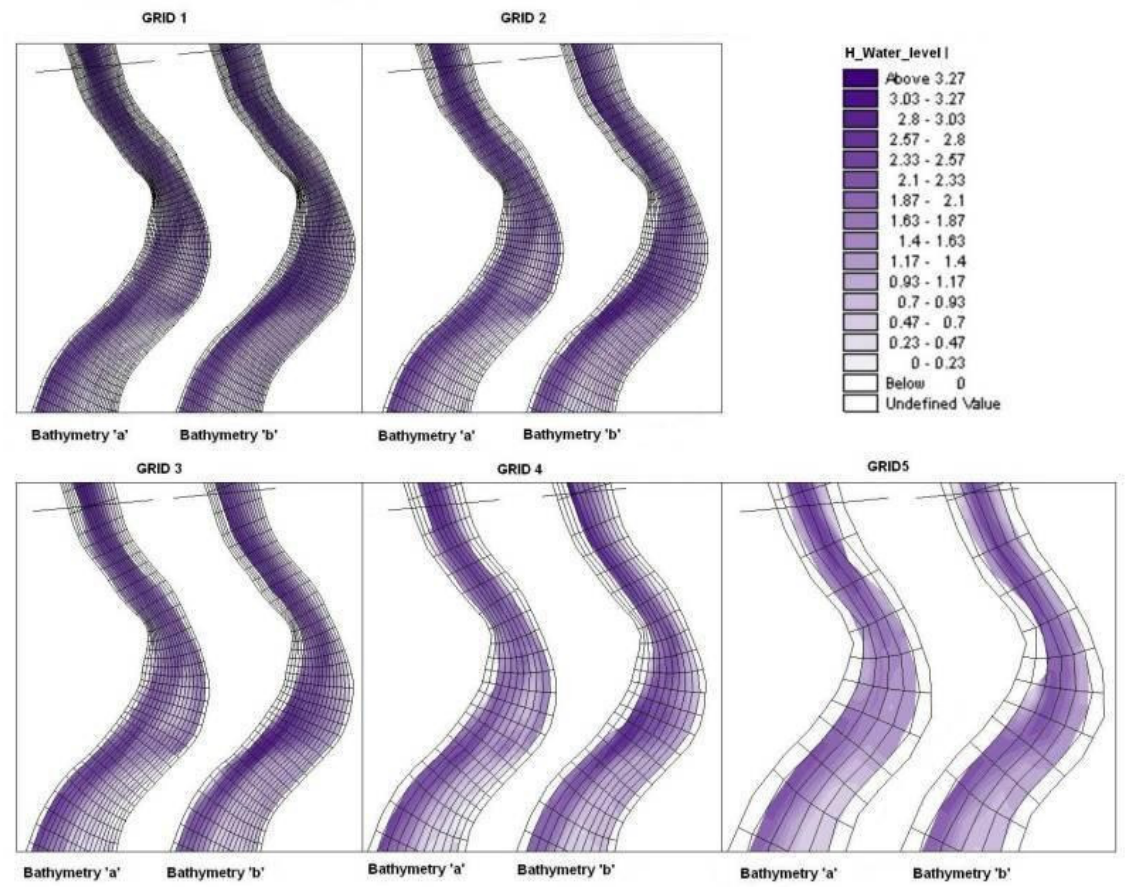

Figure 4: Comparison of simulated maximum water depth with different topographical resolutions (bathymetries 'a'-b') and cell sizes (grids 1 to 5 ). 
Analysis of morphological variations of the watercourse identified two kinds of sub-reaches: an active riverbed with alternating erosional-depositional zones (cross-sections 58 to 54) and a less active riverbed, with slightly alternating zones with erosion-deposition (cross-sections 54 to 43). The first is characterised by high morphological activity, principally on the plan-form, as shown by periodic erosional-depositional zones, migration of bars (point, lateral, central), opening of new channels near curves, and increasing outflow sections. The second is characterised by low morphological activity, due to structures, which stabilise the riverbed, revealed by dominant sediment redistribution.

A comparison between initial and final bed levels, in two representative cross-sections of both sub-reaches, is shown in fig. 5; note that, in spite of large bed elevation dissimilarity with model bathymetries ' $a$ ' and ' $b$ ', the final evolutions are closed. This fact shows that model bathymetry ' $b$ ', obtained from cross-sections, may be used as a preliminary approach for an idea of morphological evolution tendencies. Further, from the point of view of grid resolution (fig. 6), a large cell produces a raw description of bed level, with a loss of morphological details, which are important in predicting sediment transport processes. However, the overall morphological tendency of the watercourse is well represented with all grids (Figure 6(a)).

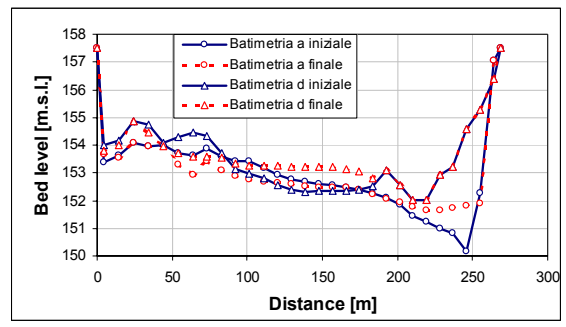

(a)

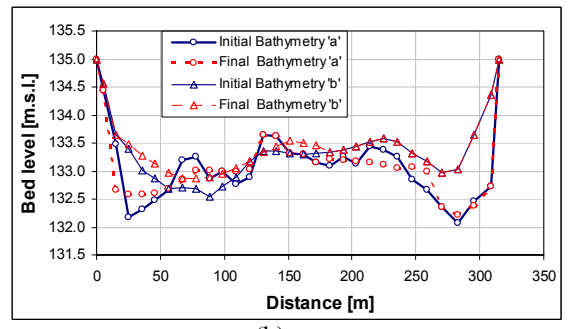

(b)

Figure 5: Bed level variations in two representative cross-sections of subreaches: (a) high and (b) low morphological activity, at beginning and end of simulations, with grid 1 and bathymetries 'a'-'b'.

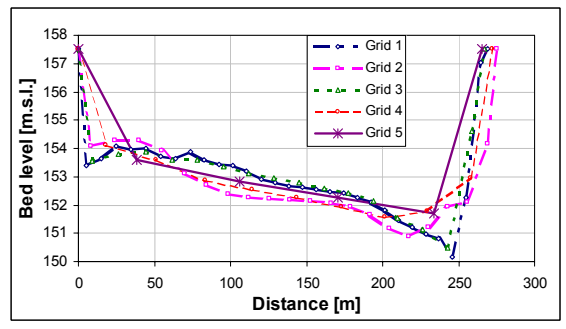

(a)

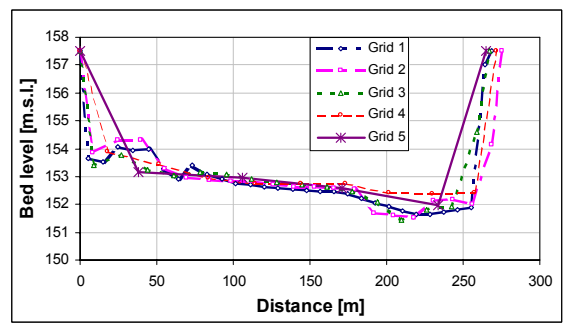

(b)

Figure 6: Comparison of bed levels at various cell resolutions in a representative cross-section with LiDAR data: (a) beginning and (b) end of simulations. 
In order to analyse the effect of model resolution on the position of erosional and depositional areas along the watercourse (fig. 7), the statistical measure of fit (Horritt and Bates [4]) was used:

$$
F=\frac{\mathrm{A}\left(\mathrm{D}_{\text {sim }} \cap \mathrm{D}_{\mathrm{obs}}\right)+\mathrm{A}\left(\mathrm{E}_{\mathrm{sim}} \cap \mathrm{E}_{\mathrm{obs}}\right)}{\mathrm{A}\left(\mathrm{D}_{\mathrm{sim}} \cup \mathrm{D}_{\mathrm{obs}}\right)+\mathrm{A}\left(\mathrm{E}_{\mathrm{sim}} \cup \mathrm{E}_{\mathrm{obs}}\right)}
$$

where $D$ and $E$ represent the surface classified as above (deposition) and below (erosion) the threshold $( \pm 10 \mathrm{~cm})$, indexes $o b s$ and sim indicate the observed and simulated surfaces, and $A(\cdot)$ gives the area. The results obtained with bathymetry ' $a$ ' and grid 1 are assumed to be the observed surface, because it presents the best resolution condition. The value of $F$ indicates if the erosional and the depositional areas are correctly predicted, and may range between $F=1$, in case of perfect fit (identical erosional and depositional areas simulated) and $F=0$, if there is no intersection between simulated and observed areas.
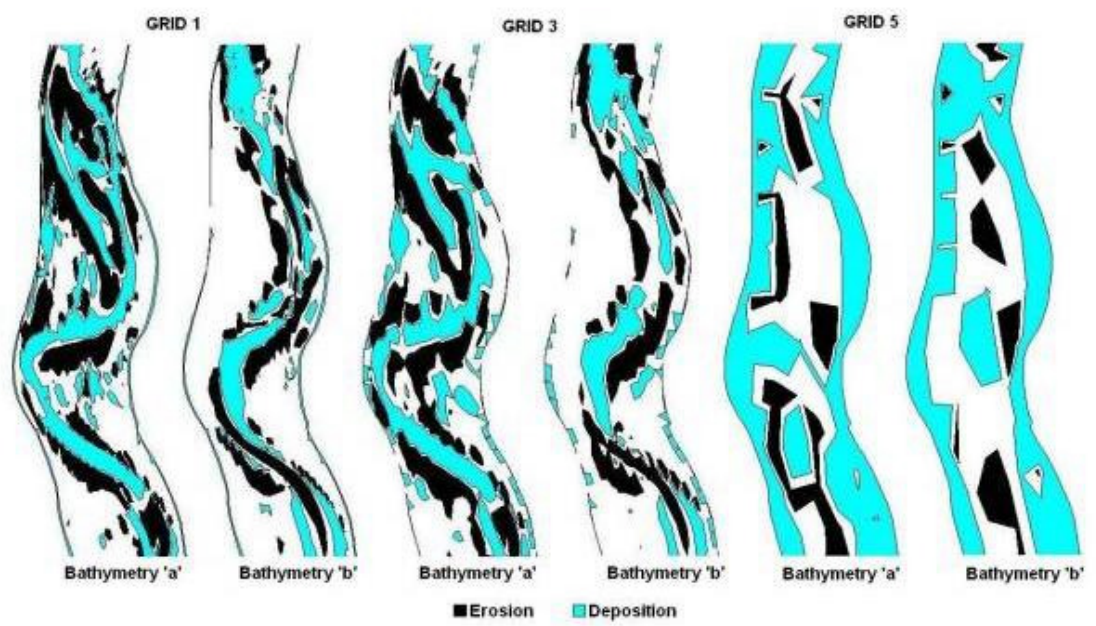

Figure 7: Erosional-depositional areas in a portion of the watercourse obtained with grids $1,3,5$, and bathymetries ' $a$ '-'b'.

Values obtained with bathymetry 'a' for grids 2-3 (fig. 8) are close to $F=0.6$, showing good spatial representation of erosional-depositional areas, while grids $4-5$, the $F$ values decrease to $0.34-0.27$, indicating that, in those cases, the results are not able to describe spatial distribution accurately. Obviously, these results are due to the grid dimension effect, as discussed above.

The $F$ values obtained with bathymetry 'b' (around 0.25 ) indicate that, for all grids, even the one with highest resolution, the model cannot identify the spatial distribution of erosional-depositional areas with sufficient precision. This, of course, is due to the lack of data between the two following cross-sections.

The results obtained with the above statistic can also be observed in fig. 7 , in which the erosional-depositional areas are similar for grids 1 and 3 with both 
bathymetries, whereas, for grid 5, they are very different. It is also important to highlight the great difference between grids 1 and 5 on the area spatial distribution obtained with both bathymetries.

Lastly, the simulation time using large cells, grid 5, is 1.5 minutes and increases with grid resolution to 33 minutes for grid 5. This may become critical when a long reach with diverse hydrological scenario, corresponding to flood waves of different return time, $T_{R}$, has to be simulated, resulting in a simulation time of several days.

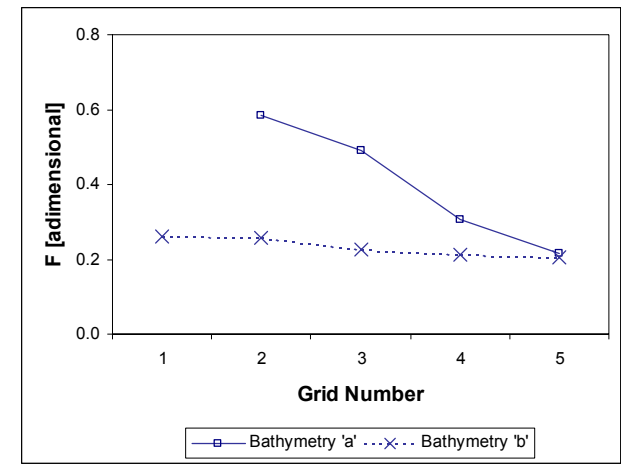

Figure 8: Comparison of $F$ values, with LiDAR and the cross-section topographic data (bathymetries 'a'-'b').

\section{Conclusions}

When a hydro-morphological model is applied, the availability of topographic data influences the results that can be obtained; the dimensions of the cells must be chosen according to the morphological features of the river.

The analysis carried out in this study, applying the bi-dimensional hydromorphological model MIKE21C on a portion of a braided river, indicates that resolution topographic data and cell dimension models produce considerable dissimilarities in simulation results; both on morphological variations (distribution of sediment transport patterns, erosion rates) and hydraulic results (flow mitigation, propagation time, water depth). Using models based on highresolution LiDAR data, accurate simulations of hydro-morphological variables characterising sediment transport were obtained. Raw bathymetric data generated from field surveys (cross-sectional data) produced a smoothing of riverbed topography between cross-sections and a consequent loss of morphological details, which do not allow accurate definition of the position of erosionaldepositional areas. However, cross-sectional data may be used as a preliminary approach to determine morphological tendencies.

Larger grid dimensions reveal a gradual loss of detail in the description of bed forms, and therefore, difficulties in reproducing the characteristics of morphological evolution. Instead, small cells accurately described sediment transport processes, but increase calculation time. 
Analysis of the spatial distribution of erosional-depositional areas simulated using LiDAR data shows that up to 16 cells (grid 3) used in the cross-sectional direction, gives sufficiently accurate results. This may be explained by considering that, in a braided river, it is essential to have a minimum number of cells (3-5) on the cross-sectional direction in order to describe each of the existing morphological features (bars, islands, multi-channels, etc.). A lower number of cells (grids 4 and 5) do not describe all these features well enough.

\section{References}

[1] Brath, A. \& Di Baldassarre, G. Effetti del grado di dettaglio dell'informazione topografica nella simulazione numerica bidimensionale. L'Acqua, 1, pp. 25-30, 2006.

[2] Casa, A., Benito, G., Thorndycraft, V.R. \& Rico, M. Efectos de las fuentes cartográficas en los resultados de la modelación hidráulica de crecidas. Ingeniería del Agua, 12(4), pp. 309-320, 2005.

[3] Haile, A.T. \& Rientjes, T.H.M. Effects of LiDAR DEM resolution in flood modelling: a model sensitivity study for the city of Tegucigalpa, Honduras. Workshop "Laser scanning 2005" Enschede, Netherlands, pp. 168-173, 2005.

[4] Horritt, M.S. \& Bates, P.D. Effects of spatial resolution on a raster based model of flood flow. Journal of Hydrology, 253, pp. 239-249, 2001.

[5] Lane, S.N. \& Richards, K.S. High resolution, two-dimensional spatial modelling of flow processes in a multi-thread channel. Hydrological Processes, 12, pp. 1279-1298, 1998.

[6] Marks, K. \& Bates, P. Integration of high-resolution topographic data with floodplain flow models. Hydrological Processes, 14, pp. 2109-2122, 2000.

[7] DHI (Danish Hydraulic Institute). MIKE 21C, scientific documentation. 2005.

[8] BETA Studio srl. Progetto preliminare per il ripristino dell'officiosità idraulica del torrente Torre mediante modellazione idraulica dell'asta del torrente torre dalla diga di Crosis, in comune di Tarcento, fino alla confluenza col Fiume Isonzo al fine della messa in sicurezza del territorio. Regione Autonoma Friuli - Venezia Giulia. Protezione Civile della Regione, OPI CD2/430.064, 2006.

[9] Smart, G.M. \& Jaeggi, M.N.R. Sediment transport on steep slopes. Mitteilung der Versuchsanstalt für Wasserbau, Hydrologie und Glaziologie der ETH Zurich, 64, pp. 19-76, 1983. 